\title{
SILICATO DE CÁLCIO COMO FONTE DE SILÍCIO PARA O ARROZ DE SEQUEIRO(1)
}

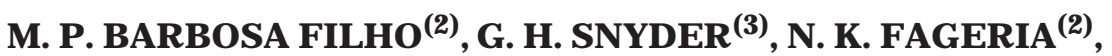 \\ L. E. DATNOFF ${ }^{(3)} \&$ O. F.SILVA(4)
}

\begin{abstract}
RESUMO
No Brasil, o arroz de sequeiro é cultivado predominantemente em solos de cerrado, os quais, em razão do seu avançado grau de intemperização, apresentam baixos valores de $\mathrm{pH}$, baixa saturação por bases e baixa relação Si/óxidos de $\mathrm{Fe}$ e Al. Assim, realizou-se um experimento em casa de vegetação, com objetivo de avaliar o efeito do silicato de cálcio no rendimento de grãos do arroz de sequei ro, bem como seu efei to corretivo na acidez do solo. Os tratamentos consistiram de seis doses de $\mathrm{SiO}_{2}$ (0; 125; 250; 375; 500 e $625 \mathrm{mg} \mathrm{kg}^{-1}$ de solo), na forma de volastonita Vansi l-10 ( $50 \%$ de $\mathrm{SiO}_{2}, 44$ de $\mathrm{CaO}$ e 1,48 de $\mathrm{MgO}$ ), e três cultivares de arroz de sequeiro (Caiapó, Carajás e Confiança), dispostos em delineamento inteiramente casualizado com quatro repetições. 0 rendimento de grãos aumentou de forma linear com a fertilização silicatada, mostrando correlação significativa e positiva com os teores de Si e Ca no solo, derivados da aplicação do silicato de cálcio. A aplicação de $\mathrm{SiO}_{2}$ aumentou o pH e os teores de $\mathrm{Ca}, \mathrm{Mg}$ trocáveis e Si solúvel no solo.
\end{abstract}

Termos de indexação: Oryza sativa L., Latossolo, correção do solo, absorção de nutriente.

\section{SUMMARY: CALCIUM SILICATE AS SOURCE OF SILICON FOR UPLAND RICE}

In Brazil, upland riceis cultivated mainly on cerrado soils, which, dueto their highly weathered degree, present low pH, low base saturation and low ratio of Si oxi des of Feand Al. A grenhouseexperiment was conducted to evaluatetheresponse of upland riceto calcium

\footnotetext{
(1) Trabal ho recebido para publicação em novembro de 1999 e aprovado em setembro de 2000.

(2) Pesquisador, Embrapa Arroz e Feijão. Caixa Postal 179, CEP 74375-000 Santo Antônio de Goiás (GO).

(3) Pesquisador, University of Florida, IFAS, Everglades Research and Education Center, P.O. Box 8003, Belle Glade 33430, USA.

(4) Economista, Embrapa Arroz e Feijão.
} 
silicateas well as its effect on correcting soil acidity. Thetreatments consisted of six levels of $\mathrm{SiO}_{2}\left(0 ; 125 ; 250 ; 375 ; 500\right.$ and $625 \mathrm{mg} \mathrm{kg}^{-1}$ of soil) as of wallastonite, Wansil-10 (50\% of $\mathrm{SiO}_{2}, 44$ of $\mathrm{CaO}$ and 1.48 of $\mathrm{MgO}$ ) and three upland rice cultivars (Caiapo, Carajas, and Confiança).Theexperimental desi gn was completely randomized with four replications. Rice responseto $\mathrm{SiO}_{2}$ was linear, showing significant positivecorre ation with $\mathrm{Si}$ and $\mathrm{Ca}$ content of soil, derived from application of calcium silicate. The application of $\mathrm{SiO}_{2}$ also increased the $\mathrm{pH}$, exchangeable $\mathrm{Ca}$ and $\mathrm{Mg}$ and solubleSi in the soil.

Index terms: Oryza sativa L., Oxi sol, soil ammendment, nutrient absorption.

\section{NTRODUÇÃO}

A planta de arroz é reconhecida mundialmente como eficiente acumuladora de Si e responsiva à fertilização silicatada. Pesquisas realizadas em sol os orgânicos (Histossolos) nosul da Flórida, nos Estados Unidos, demonstraram que a fertilização do arroz com sil icato de cál cio reduziu a incidência de brusone de 17 a $31 \%$ e da helmintosporiose de 15 a 32\% (Datnoff, et al., 1991; 1992). Prabhu et al. (1996) também demonstraram redução de $17,5 \%$ na severidade das manchas dos grãos do arroz de sequeiro e aumento de $20 \%$ no peso de grãos (média de 50 cultivares) com a aplicação de $200 \mathrm{~kg} \mathrm{ha}^{-1}$ de $\mathrm{SiO}_{2}$ na forma de volastonita. Esse efeito benéfico do silicato de cálcio para a cultura do arroz é reconhecido, não apenas por aumentar o rendimento de grãos e conferir maior resistência às plantas contra doenças fúngi cas, mas também pel o seu efeito corretivo no solo, aumentando a disponibilidade de nutrientes indispensáveis ao desenvolvimento das plantas, como oP , Ca, Mg, entre outros.

O óxido desilício $\left(\mathrm{SiO}_{2}\right)$ éo mineral primário mais abundante nos solos, constituindo a base da estrutura da maioria dos argilominerais. Todavia, em razão do avançado grau de intemperização em que se encontram os sol os das regiões tropicais, o $\mathrm{Si}$ éencontrado basicamentena forma de quartzo, opala $\left(\mathrm{SiO}_{2} \cdot \mathrm{nH}_{2} \mathrm{O}\right)$ e outras formas não-disponíveis às plantas. Como conseqüência desse processo de intemperização, esses solos apresentam sérias limitações químicas para o desenvolvimento das plantas, tais como: el evada acidez, baixa capacidade de troca catiônica (CTC), baixa saturação por bases e alta capacidade para fixar fósforo.

No Brasil, por ser o arroz de sequeiro cultivado predominantementeem solos altamenteintemperizados e por ser considerado uma planta eficiente acumuladora de Si, é possível ocorrer, à semel hança dos resultados obtidos com a aplicação de silicatos em arroz irrigado em outros países, efeitos positivos da aplicação de silicato de cál cio na cultura do arroz de sequeiro, dada sua capacidade de suprimento de Si e Ca e sua ação corretiva do solo pelo íon silicato (Elawad \& Green J r., 1979; Snyder et al., 1986).
A partir dessas informações, realizou-se um ensaio exploratório em casa de vegetação com o obj etivo de avaliar o efeito do silicato de cál ci o como fontedeSi na cultura do arroz desequeiro, bem como o seu efeito corretivo no solo.

\section{MATERIAL E MÉTODOS}

Utilizou-se um Latossolo Vermelho-Escuro distrófico (LEd) de textura argilosa. Coletaram-se amostras de solo da camada de $0-20 \mathrm{~cm}$ de profundidade em área ainda virgem da Fazenda Experimental da E mbrapa Arroz eF eijão, localizada no município deSanto Antônio deGoiás (GO). Depois de passados em peneira de $5 \mathrm{~mm}$, seis quilos da amostra de sol o foram col ocados em vasos plásticos e adubados com N-P-K e micronutrientes nas quantidades, fontes e formas de aplicação especificadas no quadro 1.

Antes da aplicação dos tratamentos, uma subamostra do sol o seca ao ar e passada em peneira de $2 \mathrm{~mm}$ foi utilizada para caracterização química do solo, segundo EMBRAPA (1997). As características analizadas foram: $\mathrm{pH}$ em água $(1: 2,5)$ 5,2; $15 \mathrm{mmol}_{\mathrm{C}} \mathrm{dm}^{-3} \mathrm{de} \mathrm{Ca}^{2+}+\mathrm{Mg}^{2+} 4 \mathrm{mmol}_{\mathrm{C}} \mathrm{dm}^{-3} \mathrm{de}$ $\mathrm{Al}^{3+} 2,0 \mathrm{mg} \mathrm{dm}^{-3}$ de $\mathrm{P} ; 40$ de $\mathrm{K} ; 0,8$ de Zn e $16 \mathrm{~g} \mathrm{~kg}^{-1}$ dematéria orgânica. Fósforo, $\mathrm{K}$ eZn foram extraídos pelo Mehlich-1. O P foi determinado por colorimetria, o K por fotometria de chama e Zn por espectrofotometria de absorção atômica. A matéria orgânica foi estimada pelo método de Walkley-Black. O teor de Si solúvel em ácido acético 0,5 mol L-1 (Snyder, 1991) foi de $13 \mathrm{mg} \mathrm{dm}^{-3}$.

Os tratamentos consistiram de três cultivares de arroz (Caiapó, Carajás e Confiança) e seis doses de $\mathrm{SiO}_{2}\left(0 ; 125 ; 250 ; 375 ; 500\right.$ e $625 \mathrm{mg} \mathrm{kg}^{-1}$ de solo) na forma de volastonita, fornecida pela I piranga Química de São Paulo (nome comercial, Vansil-10) com $50 \%$ de $\mathrm{SiO}_{2}, 44 \%$ de $\mathrm{CaO}$ e $1,48 \%$ de $\mathrm{MgO}$. A volastonita foi misturada ao solo manualmente em cada vaso, irrigado, posteriormente, até aproximadamente $70 \%$ da capacidade máxima de retenção de água. Semanalmente, os vasos foram 


\section{Quadro 1. Concentração de nutrientes, fontes e respectivas quantidades adicionadas ao solo, no plantio e durante o período de crescimento do arroz}

\begin{tabular}{lcclcc}
\hline Nutriente & Concentração total & Solução & \multicolumn{1}{c}{ Fonte } & Plantio & Cobertura \\
\hline & $\mathrm{mg} \mathrm{kg}^{-1}$ & $\mathrm{~g} \mathrm{~L}^{-1}$ & & $-\mathrm{ml}^{6} \mathrm{~kg}^{-1}$ de solo - \\
$\mathrm{N}$ & 200 & 72,0 & $\mathrm{NH}_{4} \mathrm{NO}_{3}$ & 25 & 25 \\
$\mathrm{P}^{(1)}$ & 200 & - & Superfosfato triplo & - & - \\
$\mathrm{K}^{(1)}$ & $150(75+75)$ & - & $\mathrm{KCl}$ & - & - \\
$\mathrm{B}$ & 1,0 & 2,28 & $\mathrm{Bórax}$ & 15 & - \\
$\mathrm{Mo}$ & 0,15 & 0,52 & $\left(\mathrm{NH}_{4}\right)_{6} \mathrm{M} \mathrm{O}_{7} \mathrm{O}_{24} 4 \mathrm{H}_{2} \mathrm{O}$ & 15 & - \\
$\mathrm{Cu}$ & 1,0 & 1,57 & $\mathrm{CuSO}_{4} .5 \mathrm{H}_{2} \mathrm{O}$ & 15 & - \\
$\mathrm{Zn}$ & 5,0 & 7,60 & $\mathrm{ZnSO}_{4} .7 \mathrm{H}_{2} \mathrm{O}$ & 15 & - \\
& & & &
\end{tabular}

(1) P e K foram aplicados na forma sólida e demais nutrientes na forma de solução. O N e o K foram parcelados em duas vezes, metade aplicada no plantio e metade em cobertura, no início do aparecimento do primórdio floral.

mudados de posição e onível deumidadefoi mantido pela adição de água destilada por meio de pesagens diárias dos vasos. O delineamento experimental foi o inteiramente casualizado, com quatro repetições, com três plantas por vaso. O experimento teveinício em novembro de 1997. A proximadamente 120 dias após a emergência do arroz, foi realizada a col heita do ensaio para determinação do rendimento de grãos por planta e da concentração de Si na palha e na casca dos grãos de arroz, segundo método de Elliott \& Snyder (1991). A quantidade de Si acumulada na palha foi calculada com base na concentração de Si e na produção por planta de matéria seca da palha.

Em amostras de solo, analisaram-se, após col heita, o Ca e o Mg trocáveis segundo EMBRAPA (1997), e o Si solúvel em ácido acético 0,5 mol L-1, segundo Snyder (1991).

Para avaliar os dados, utilizaram-se as análises de variância e de regressão disponíveis no pacote Statistical Analysis Sistem (SAS, I nstitute, 1990).

\section{RESULTADOS E DISCUSSÃO}

Houve efeito significativo atribuído às doses de $\mathrm{SiO}_{2}$ no rendimento de grãos ( $\mathrm{P}<0,01$ ), não havendo diferenças entre cultivares ou da interação doses $x$ cultivares. O rendimento de grãos aumentou significativamente e de forma linear com as doses de $\mathrm{SiO}_{2}$ (Figura 1a). A equação de regressão obtida $(\mathrm{Y}=3,800+0,002 \mathrm{X})$ apresentou um coeficiente de determinação $\left(r^{2}\right)$ de 0,724 ( $\left.P<0,01\right)$. A extrapolação da dose máxima aplicada de $\mathrm{SiO}_{2}$ para as condições de campo, que equivale a $1,25 \mathrm{tha}^{-1}$ de $\mathrm{SiO}_{2}$, demonstra a alta capacidade de resposta do arroz de sequeiro ao silicato de cálcio.
O aumento de rendimento de grãos de acordo com a fertilização silicatada (Figura 1a) pode ser relacionado com o aumento na disponibilidade de Si e Ca derivados da aplicação do silicato de cálcio (Quadro 2). Deve-se ressaltar, entretanto, que, por não ter sido feita a compensação do Ca contido na volastonita, torna-se difícil atribuir isoladamente o efeito do Ca ou do Si no rendimento de grãos.

No entanto, em experimentos de avaliação de silicato de cál cio para a cultura do arroz, Elawad \& Green J r. (1979), Snyder et al. (1986) e Korndörfer et al. (1999) também atribuíram o aumento de rendimento de grãos à ação corretiva do solo promovida pelo íon silicato e ao aumento da disponibilidade de Si, Ca e Mg para as plantas.

Em áreas de cerrado, é comum alguns solos mostrarem-se deficientes em $\mathrm{Ca}$ e $\mathrm{Mg}$, sem que apresentem problemas de toxidez de Al. Em tais condições, a simples fertilização com Ca e Mg tem sido suficiente para elevar os níveis desses nutrientes nosolo e provocar aumentos significativos de produtividade. Exemplo disso foi relatado por Fageria (1984), em que a el evação do nível de $\mathrm{Ca}+\mathrm{Mg}$ no solo de 6,0 para $49,0 \mathrm{mmol}_{\mathrm{c}} \mathrm{cm}^{-3}$, pela calagem, provocou um aumento de $23 \%$ no rendimento de arroz.

Analisando o efeito do Si, Tanaka \& Yoshida (1970) relataram ser esteelemento muito importante para a cultura do arroz. Segundo esses autores, esta planta, por ser considerada eficiente acumuladora deSi, apresenta mai or resistência contra a incidência de doenças fúngicas e, geral mente, émais produtiva em sol os com níveis mais el evados de Si "disponível".

Considerando a ausência de efeito significativo do cultivar e da interação de doses de $\mathrm{SiO}_{2}$ ecultivares, avaliaram-se os efeitos das doses de $\mathrm{SiO}_{2}$ no teor de Si na casca (Figura 1c), a média das três cultivares. 
Quadro 2. Coeficiente de correlação linear simples entre características do solo e da planta, considerando a média de três cultivares de arroz de sequeiro

\begin{tabular}{|c|c|c|c|}
\hline Característica & Si na palha & Acúmulo de Si na planta & Rendimento de grãos \\
\hline pH em água & $0,2269^{\text {ns }}$ & $0,2706 *$ & $0,2181^{\mathrm{ns}}$ \\
\hline Ca trocável & $0,5828^{* * *}$ & $0,6492^{* * *}$ & $0,4128^{* * *}$ \\
\hline Mg trocável & $0,3033^{* *}$ & $0,3388 * *$ & $0,1476^{\text {ns }}$ \\
\hline Si solúvel(1) & $0,6451^{* * *}$ & $0,6452^{* * *}$ & $0,3862 * * *$ \\
\hline
\end{tabular}

*, **, *** Indicam P <0,05; P <0,01 e P <0,001, respectivamente; ns = não significativo. ${ }^{(1)}$ Ácido acético 0,5 mol L-1.

O efeito das doses de $\mathrm{SiO}_{2}$ sobre esta característica foi linear $(P<0,001)$. A concentração deSi da casca dos grãos aumentou de $0,6 \mathrm{~g} \mathrm{~kg}^{-1}$, notratamento sem adição de $\mathrm{SiO}_{2}$, para $1,28 \mathrm{~g} \mathrm{~kg}^{-1}$, na dose máxima aplicada de $625 \mathrm{mg} \mathrm{kg}^{-1}$ de solo (Figura 1c).

Embora as diferenças de absorção de Si entre cultivares de sequeiro e irrigados devam ser vistas com restrições, Majunder et al. (1985) também relataram ampla faixa de variação na acumulação deSi em vários genótipos de arroz irrigadocultivados em solos deficientes em fósforo.

Apesar dos grandes aumentos na concentração de $\mathrm{Si}$ com as doses crescentes de $\mathrm{SiO}_{2}$, os valores encontrados nestetrabal ho mostraram-seinferiores a 5\%, proposto como mínimo por Yoshida (1981) para arroz irrigado cultivado em solos minerais, e ligeiramente superiores a 3\% (nas doses mais elevadas de $\mathrm{SiO}_{2}$ ), recomendado por Snyder et al. (1986) como mínimo para arroz cultivado em solos orgânicos. Segundo esses autores, o teor de Si no tecido vegetal pode ser considerado um indicador de resposta da cultura do arroz ao Si "disponível" no solo.

Embora o teor de Si na palha do arroz possa variar de acordo com o ecossistema de cultivo dessa cultura, os teores encontrados neste trabalho (Figura 1b) mostraram-se muito abaixo daqueles relatados para arroz irrigado. Lian (1976), baseado em vários experimentos de resposta do arroz ao Si, correlacionou o teor de Si na palha do arroz com rendimento de grãos, concluindo que o teor crítico na palha é de $60 \mathrm{~g} \mathrm{~kg}^{-1}$ de Si (com base em peso de matéria seca), no J apão e Coréia, e de $50 \mathrm{~g} \mathrm{~kg}^{-1}$, em Taiwan. Já em solos orgânicos (Histossolos) da área agrícola dos Everglades no sul da Flórida, Snyder et al. (1986) recomendam a aplicação de silicato de cálcio sempre que o teor de Si na palha do arroz for menor que $30 \mathrm{~g} \mathrm{~kg}^{-1}$ e o Si no solo extraído em ácido acético $0,5 \mathrm{~mol} \mathrm{~L}^{-1}$ for igual ou inferior a $10 \mathrm{mg} \mathrm{dm}^{-3}$.

Uma explicação factível para essas diferenças de teores de Si encontrados em plantas de arroz de sequeirono Brasil e de cultivares irrigados dos Países Asiáticos pode ser atribuída às diferenças de potencial produtivo das próprias culturas (arroz de sequeiro e irrigado), à diferença de método empregado para análise de Si no tecido vegetal e às características edafológicas dos solos.

Os três cultivares avaliados apresentaram a mesma resposta (linear) à aplicação de doses de $\mathrm{SiO}_{2}$ quanto ao acúmulo deSi na pal ha ena planta, sendo o cultivar Confiança o genótipo que apresentou o maior acúmulo de $\mathrm{Si}$, seguido pelos demais cultivares (Figura $1 \mathrm{~b}$ e d). Admitindo que a acumulação de Si noteci do vegetal esteja diretamente relacionada com a resistência das plantas às doenças fúngicas, cujo mecanismo de resistência mais aceito é de natureza mecânica, equea penetração do patógeno seja menor em plantas com teores mais elevados de Si, decorrente da barreira mecânica formada pela deposição de sílica na epiderme da fol ha, a estratégia de aumentar a quantidade de Si na planta de arroz deve ser considerada uma alternativa importante de manejo integrado, visando ao controle de doenças do arroz de sequeiro.

A aplicação de silicato de cálcio promoveu aumentos lineares esignificativos nos valores depH, nos teores de $\mathrm{Ca}$ e $\mathrm{Mg}$ trocáveis e nos teores de $\mathrm{Si}$ solúvel em ácido acético (Figura 2). Resultado idêntico foi relatado por Korndörfer et al. (1999), que avaliaram o efeito de doses de vol astonita sobre esses atributos de quatro solos representativos da região decerrado. A mel horia desses atributos químicos do solo ( $\mathrm{pH}, \mathrm{Ca}, \mathrm{Mg}$ e Si ) e os aumentos de rendimento de grãos e teores de Si na planta, considerando a aplicação de silicato de cálcio, podem ser explicados pela composição da volastonita $(50 \%$ de $\mathrm{SiO}_{2}, 44$ de $\mathrm{CaO}$ e 1,48 de $\mathrm{MgO}$ ) e pela sua ação corretiva no solo. A el evação do pH ocorre segundo reações apresentadas em Korndörfer et al. (1999), pelo aumento da concentração de hidroxilas liberadas durante a dissolução do silicato de cál cio no solo.

Portanto, o efeito benéfico da fertilização silicatada para a cultura do arroz de sequeiro não 

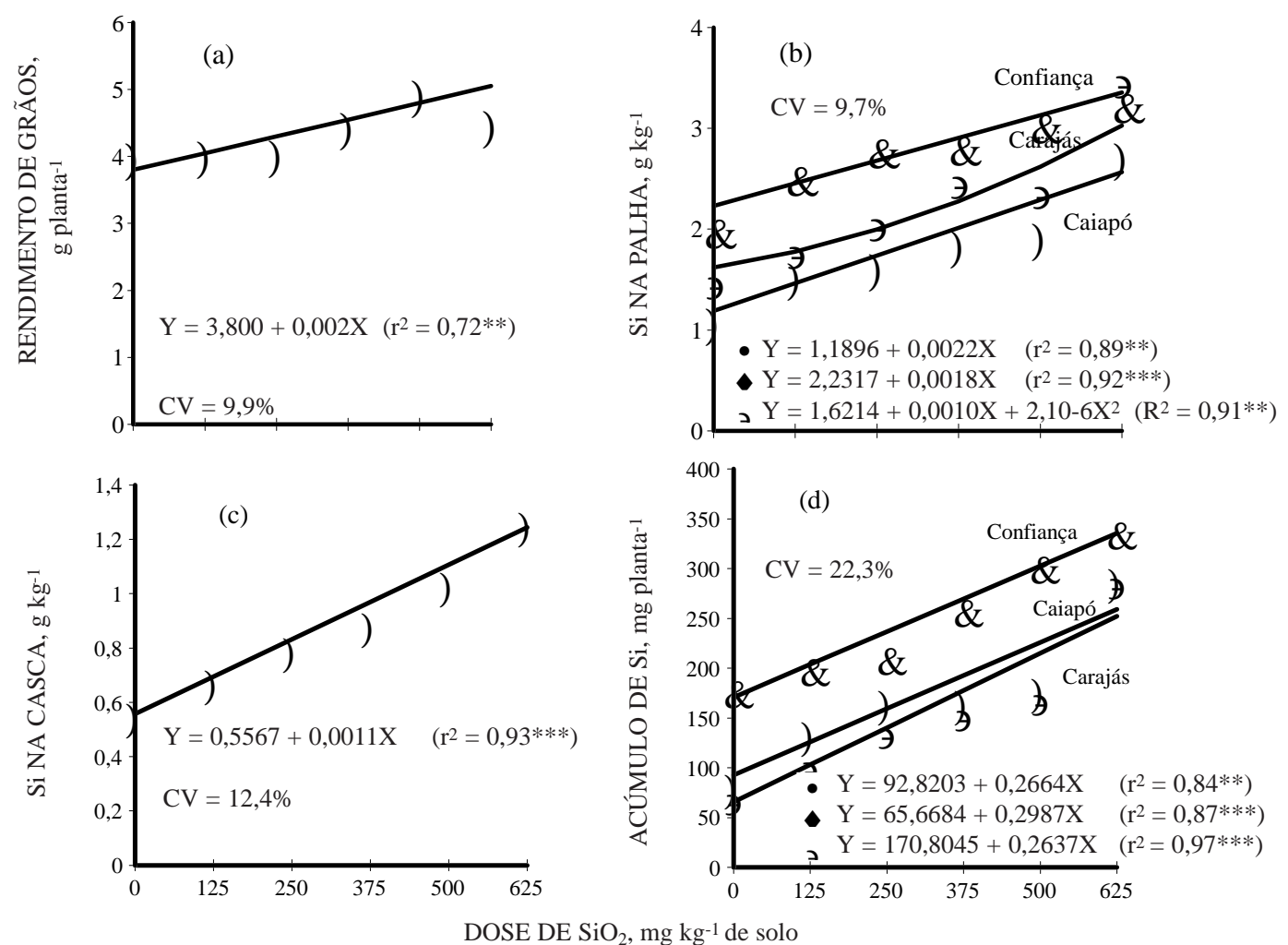

Figura 1. Características de planta influenciadas pela aplicação de doses de $\mathrm{SiO}_{2}$ (volastonita) em Latossolo Vermelho-E scuro distrófico (a) rendimento de grãos, (b) teor de Si na palha, (c) teor de Si na casca e (d) acúmulo de Si na planta. ** $e^{* * *}$ indicam $P<0,01$ e $P>0,001$, respectivamente.
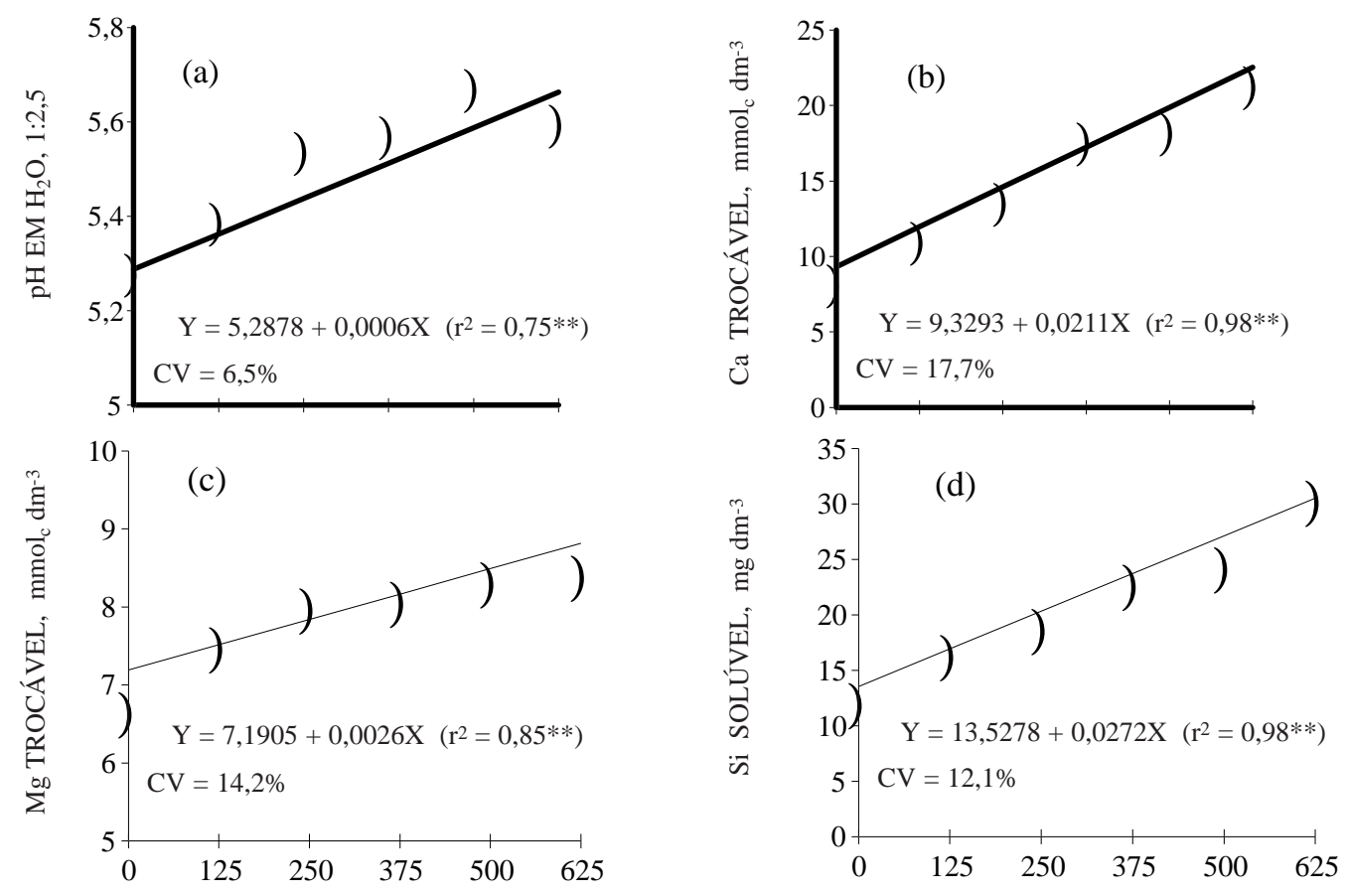

DOSE DE $\mathrm{SiO}_{2}, \mathrm{mg} \mathrm{kg}^{-1}$ de solo

Figura 2. Características de solo influenciadas pela aplicação de doses de $\mathrm{SiO}_{2}$ (volastonita) em Latossolo Vermel ho-E scuro distrófico (a) pH em água, (b) Ca trocável, (c) Mg trocável e Si solúvel (áci do acético $\left.0,5 \mathrm{~mol} \mathrm{~L}^{-1}\right)$. **, *** indicam $\mathrm{P}<0,01$ e $\mathrm{P}<0,001$, respectivamente. 
deveser atribuído apenas a um de seus constituintes isol adamente, mas, sobretudo, à sua ampla atuação como corretivo de acidez, criando mel hor es condições químicas no sol o para o desenvolvimento das plantas. Adicionalmente, considerando a importância do Si para a cultura do arroz, mais especificamente, por conferir maior resistência das plantas à incidência de doenças, a utilização do silicato de cálcio como fonte de Si e Ca para as plantas pode ser mais vantajosa comparativamente a outros corretivos de solo, pois, além de sua ação neutral izante de acidez, promove aumentos da disponibilidade de Si no solo e, conseqüentemente, facilita sua absorção pelas plantas (Figuras 1 e 2).

\section{CONCLUSÕES}

1. O arroz de sequeiro respondeu positivamente e deforma linear à aplicação desilicato de cálcio, quanto ao rendimento de grãos eacumulação de Si na planta.

2. A aplicação de silicato de cálcio na forma de volastonita promoveu aumentos de $\mathrm{pH}$, dos teores de Ca e Mg trocáveis e do teor de Si solúvel do solo.

\section{LITERATURA CITADA}

DATNOFF, L.E.; RAID, R.N.; SNYDER, G.H. \& J ONES, D.B. Effect of calcium silicate on blast and brown spot intensities and yields of rice. Plant Dis., 75:729-732, 1991.

DATNOFF, L.E.; SNYDER, G.H. \& DEREN, C.W. Influence of silicon fertilizer grades on blast and brown spot development and on rice yields. Plant Dis., 76:1182-1184, 1992.

ELAWAD, S.H. \& GREEN J r., V.E. Silicon and the rice plant environment: A review of recent research. II Riso, 28:235253, 1979.
ELLIOTT, C.L. \& SNYDER, G.H. Autoclave-Induced digestion for the colorimetric determination of silicon in rice straw. J . Agric. Food Chem., 39:1118-1119, 1991.

EMPRESA BRASILEIRA DE PESQUISA AGROPECUÁRIA EMBRAPA. Serviço Nacional de Levantamento e Conservação de Solos (Rio de J aneiro, RJ ). Manual de métodos de análise de solo. Rio de J aneiro, 1979. 282p.

FAGERIA, N.K. Resposta de cultivares de arroz à aplicação de calcário em solo de cerrado. Pesq. Agropec. Bras., 19:883889, 1984

KORNDÖRFER, G.H.; ARANTES, V.A.; CORRÊA, G.F. \& SNYDER, G.H. Efeito do silicato de cál cio no teor de silício no solo e na produção de grãos de arroz de sequeiro. R. Bras. Ci. Solo, 23:635-641, 1999.

LIAN, S. Silica fertilization of rice. In: LIAN, S., ed. The fertility of paddy soils and fertilizer applications for rice. Taipei, Food Fertilizer Tecnology Center, 1976. p.197-220.

MAJ UNDER, N.D.; RAKSHIT, S.C. \& BORTHAKUR, D.N . Genetics of silica uptake in selected genotypes of rice (Oryza sativa L.). Plant Soil, 88:449-453, 1985.

PRABHU, A.S.; BARBOSA FILHO, M.P.; FILIPPI, M.C. \& DYNIA, J .F. I nfluência de fertilização com Si sobre mancha de grãos em arroz. In: CONGRESSO BRASILEIRO DE FITOPATOLOGIA, 29, Campo Grande, 1996. Resumos. Fitopatol. Bras., 21:405, 1996.

SAS I nstitute. SAS/STAT. Software. Version 6, Cary, 1990. 50p.

SNYDER, G.H. Development of a silicon soil test for Histosolgrown rice. Belle Glade, University of Florida, 1991. (Belle GladeEREC Res. Rep.EV-1991-2)

SNYDER, G.H.; J ONES, D.B. \& GASCHO, G.J. Silicon fertilization of rice on Everglades Histosols. Soil Sci. Soc. Am. J ., 50:1259-1263. 1986.

YOSHIDA, S. Fundamentals of rice crop science. Los Baños, International Rice Research Institute, 1981. 269p.

TANAKA, A. \& YOSHIDA, S. Nutritional disorders of the rice plant in Asia. Los Bãnos, International Rice research Institute, 1970. 51p. (IRRI. Technical Bulletin, 10) 